\title{
THE EGG AS FOOD
}

$\mathrm{O}$ $\mathrm{NE}$ of the most difficult of the tasks which has always confronted the scientific worker possessed of a proper appreciation of his responsibilities to society has been the choice of a way of making his results known so that they will do most good. Material of an abstruse or technical nature is fitly presented to a learned society. Such a society, however, only comprises producers of knowledge. It is much more difficult to pass on knowledge to the consumers : those who make use of it. Nutrition is a branch of science which applies so directly to the population at large that any attempt to shorten the distance between the scientific investigator and the dining-table is to be viewed with especial interest.

The Nutrition Panel of the Society of Chemical Industry, the membership of which is made up of workers in all branches of science ranging from the academic Scylla of biological oxidations and reductions to the practical Charybdis of canning, has conceived itself to be peculiarly well fitted for the task of disseminating the knowledge of nutrition. A series of meetings has been planned at each of which a single food will be discussed. These meetings are not addressed to a purely scientific audience, neither are they intended to be 'popular'. Rather are they for all those whose business it is to take an intelligent interest in nutrition.

The first meeting of the series was held on April 24 and was concerned with the egg as food. Besides the members of the Society of Chemical Industry itself, representatives of educational, agricultural, and medical associations were invited, as well as members of the great women's associations interested in general welfare.

Dr. Joseph Needham, of the Biochemical Laboratory, University of Cambridge, who spoke on "The Biological Nature of the Egg", pointed out how complex is the structure of the eggs of birds and other vertebrates. In fact the embryo, which is eventually to develop into the new animal, only occupies a very small space within the whole egg. The remainder serves, in one way or another, to keep the organism alive until it is hatched. It is interesting to note that this is not the case among lower animals. The young octopus in its egg is not supplied by its mother with enough copper with which to make its blood pigment, but must obtain more for itself from the surrounding sea. Newts and frogs in their eggs also depend on the environment for water. Birds' eggs, however, represent a type of perfectly 'closed-box' structure which requires many ingenious devices in order to survive. One of these, by which the bird saves itself from being poisoned by its own by-products, is the fact that the developing embryo does not excrete nitrogen as ammonia or urea but in the form of uric acid, which is more easily deposited as crystals.

Dr. Ethel M. Cruickshank, of the Department of Agriculture, University of Cambridge, who spoke on the "Chemical Composition of the Egg", pointed out that the hen can be regarded as a physiological machine for turning raw materials into human foodstuffs. The amount of such human food that the hen can produce in a day depends on a number of factors, but to a large extent it is true to say that the bigger the hen the larger the egg. The number of eggs a hen lays in a year is a different matter; an interesting point is the fact that high production has little or no detrimental effect on the quality of the eggs. In considering the composition of the egg one must divide it into three parts. The shell is principally made up of calcium carbonate, although small amounts of magnesium, phosphorus and organic matter are present. 'The 'white' is composed of at least four different proteins and can be divided into layers of thick and thin white. The proportion of thick to thin white influences the culinary value of the egg. Together, the proteins in the white contain all the essential amino acids for 'first-class' protein. Egg white contains minerals and also supplies valu. able amounts of vitamin $B_{2}$. The yolk contains two proteins which are also found to be of 'first-class' quality. Besides protein the yolk contains 30-32 per cent fat. Numerous minerals are present, including relatively large amounts of easily assimilable iron. Vitamins $A, D, B_{1}$ and riboflavin are also present. The anti-rachitic vitamin D is of great significance in the diet. Dr. Cruickshank also discussed the factors in the diet of the hen which might give the yolk an unpleasant taste or a strange colour. Although the amount of fat, and hence the total food value of the egg, can only be influenced to a slight extent by the diet of the hen, the nature and flavour of the egg can be very strikingly altered by feeding mashes containing, for example, hemp seed or linseed oil. As to vitamins, it is essential that they should be abundantly present in the diet of the hen in order that her eggs may be of high nutritive value: and it is well known that a thin shell is obtained by feeding a hen a diet poor in calcium. However, the calcium contents of the yolk and the white are not affected. The amount of iodine in eggs is affected by the amount in the hens' food, although iron and copper appear to be independent of the amount present in the diet.

Dr. S. K. Kon, of the National Institute for Research in Dairying, Reading, spoke on the nutritive importance of eggs in the diet. He stressed that eggs share with milk the ability to cover nutritive requirements during the period of rapid development. The shortage of vitamin $\mathrm{D}$ and iron in milk is admirably supplemented by eggs; the deficiency of eggs in calcium is made good by their association with milk. The vitamins, minerals and 'first-class' protein in eggs make them one of the protective foods. In particular, eggs supplement very well the proteins present in cereals. Dr. Kon showed in detail how eggs contribute to the various factors of a good diet.

Dr. R. B. Haines, of the Low Temperature Research Station, Cambridge, spoke on the preservation of eggs. He pointed out that hens' eggs are in a state of rapid change. The aim of storage is to retard or stop this change and prevent the attack of outside agencies such as micro-organisms. Although storage only affects the nutritive value of eggs to a very minor degree, any loss of palatability and cooking quality is a clear indication that certain slight chemical changes have taken place. Dr. Haines mentioned three methods for the large-scale storage of eggs-cold storage, storage with the partial addition of carbon dioxide, and full gas storage. For other purposes, drying or freezing can be used. Problems connected with the storage of eggs lead to 
the consideration of questions of production and handling. For example, 'thick white' is apparently due to the individual hen. Again, spoilage of eggs by the invasion of bacteria is influenced by the structure of the egg-shell, which may vary greatly in successive eggs from the same hen or by the "washing' treatment which the eggs receive. Among many other topics upon which Dr. Haines touched were 'swollen' and 'flabby' yolks due to loss of moisture, 'watery whites', 'sunken' and 'sided' yolks due to chemical changes and eggs with 'whiskers' due to the growth of fungus on the shell.

Miss Mary Andross, of the West of Scotland College of Domestic Science, Glasgow, gave the final paper on the subject of "The Cooking of Eggs". Research in domestic science concerns itself with the effects such factors as temperature, time, rate of cooking, acidity, or the addition of salts may have on the nutritive properties of eggs which are boiled, poached, fried, scrambled or made into omelets, custards, mayonnaise, meringues, angel cakes, or sponge cakes. Another important factor which is the subject of scientific investigation is the effect of the age of the egg in relation to its cooking qualities. Miss Andross presented the results of a large amount of her own original work on these points. She also discussed the waste of food value which may take place in different methods of cooking. In making a scrambled egg, for example, $13 \cdot 5$ per cent of the original food value is left behind in the various bowls and dishes used in cooking it. Miss Andross concluded by discussing the effects which different treatments may have on the digestibility of the food.

In the course of a general discussion a number of further points were considered. These included the 'too fresh' egg; the problem of sensitivity to egg white; coagulation of egg proteins during cooking; reconstitution of dried eggs; and many others.

If the following meetings of the series on other foods are as complete as the first, the collected papers will form a text-book of unrivalled excellence. It would only then remain to see whether the farmers, administrators, cooks and diners of England are availing themselves of the information thus collected to determine whether the plans of the Nutrition Panel have succeeded.

\title{
FUNDAMENTALS OF CLASSICAL ELECTRIC AND MAGNETIC THEORY
}

\author{
By Dr. G. BurNiston BRown \\ University COLLEge, LONDON
}

$\mathrm{E}^{\mathrm{v}}$ VER since the Committee of the International Electrical Congress in 1932 was forced to resort to a majority vote in order to decide upon the introduction of the Oersted, the general uneasiness of physicists with regard to the difference between induction and force has been augmented rather than allayed; and all the more so when the secretary of the committee, Prof. Henri Abraham, maintained that there were at least six definitions of the permeability $(\mu)$, and that it is not possible either to show that they are the same or different?

A meeting of the Physical Society on May 3 was devoted to this problem and to a discussion of the presentation of the classical theory of electricity and magnetism in general. The discussion was opened by the present writer, who claimed to show that the first three definitions of $\mu$, which are fundamental to electromagnetic theory, are equivalent. Abraham's last three definitions are concerned with magnetooptics and are not of the same importance.

In order to demonstrate this equivalence the author made use of a point of view which is gaining ground among writers on the philosophy of science, namely, that the ultimate meaning of any concept to which numbers are attached involves the consideration of an act of measurement either in an actual experiment or in a "theoretical-experiment". This may be looked upon as a special form of the general thesis put forward by Ogden and Richards in their book "The Meaning of Meaning", that all meaning involves what they termed a "sign-situation". In the special form given above, it is the basis of Sir Arthur Fddington's philosophy of science, and he has called a sign-situation a "gesticulation"s.

If this principle is applied to the concepts of "force on a pole" and "force on a current element", it can be shown that the former requires a rodshaped cavity and the latter a disk-shaped cavity for the act of measurement, and thus the cavities of the classical treatment of Maxwell and Kelvin arise naturally instead of arbitrarily. Application of the same method to the theoretical-experiment in which the principle of the conservation of energy is used to show that the induced electromotive force is equal to the rate of change of magnetic flux, shows clearly that it is the rate of change of the normal induction which is involved and not the force. This is not often shown clearly in the text-books.

Use can be made of Poisson's fictitious-layer theory to find the force in the cavities. Poisson's treatment rests solely on the inverse square law, and the assumption that the field of a polarized substance can be treated as consisting of the fields of a large number of doublets. If we take the number of doublets per cubic centimetre to be $n$ and their polarizability $\alpha$, then we readily find the relation with $K$, the dielectric constant, to be

$$
K=1+4 \pi n \alpha \text {. }
$$

This formula is derived directly from classical macroscopic theory and has the great advantage that it is independent of theories of molecular structure. It assumes that the polarization is proportional to the internal field but is independent of whether the polarization is due to separation of charges or rotation of doublets already present. It seems that Mossotti took the polarization to be proportional to the external field, and this causes his formula to. differ from that given above. The formula of Clausius, since made great use of by Lorentz and Debye, would, however, seem to involve an unjustifiable mixture of macroscopic and microscopic considerations. One way of putting it briefly is this: a piece of 